\title{
Planar millimeter wave radar frontend for automotive applications
}

\author{
J. Grubert ${ }^{1}$, J. Heyen ${ }^{1}$, C. Metz ${ }^{2}$, L. C. Stange ${ }^{1}$, and A. F. Jacob ${ }^{1}$ \\ ${ }^{1}$ Institut für Hochfrequenztechnik, Technische Universität Braunschweig, Postfach 3329, 38023 Braunschweig, Germany \\ ${ }^{2}$ Network Hardware Integration Research Department, Bell Laboratories, Murray Hill, NJ 07974, USA
}

\begin{abstract}
A fully integrated planar sensor for $77 \mathrm{GHz}$ automotive applications is presented. The frontend consists of a transceiver multichip module and an electronically steerable microstrip patch array. The antenna feed network is based on a modified Rotman-lens and connected to the array in a multilayer approach offering higher integration. Furthermore, the frontend comprises a phase lock loop to allow proper frequency-modulated continuous wave (FMCW) radar operation. The latest experimental results verify the functionality of this advanced frontend design featuring automatic cruise control, precrash sensing and cut-in detection. These promising radar measurements give reason to a detailed theoretical investigation of system performance. Employing commercially available MMIC various circuit topologies are compared based on signal-tonoise considerations. Different scenarios for both sequential and parallel lobing hint to more advanced sensor designs and better performance. These improvements strongly depend on the availability of suitable MMIC and reliable packaging technologies. Within our present approach possible future MMIC developments are already considered and, thus, can be easily adapted by the flexible frontend design.
\end{abstract}

Es wird ein integrierter planarer Sensor für $77 \mathrm{GHz}$ Radaranwendungen vorgestellt. Das Frontend besteht aus einem Sende- und Empfangs-Multi-Chip-Modul und einer elektronisch schwenkbaren Antenne. Das Speisenetzwerk der Antenne basiert auf einer modifizierten RotmanLinse. Für eine kompakte Bauweise sind Antenne und Speisenetzwerk mehrlagig integriert. Weiterhin umfasst das Frontend eine Phasenregelschleife für eine präzise Steuerung des frequenzmodulierten Dauerstrichradars. Die aktuellen Messergebnisse bestätigen die Funktionalität dieses neuartigen Frontend-Designs, das automatische Geschwindigkeitsregelung, Kollisionswarnung sowie Nahbereichsüberwachung ermöglicht. Die Qualität der

Correspondence to: J. Grubert

(J.Grubert@TU-Braunschweig.de)
Messergebnisse hat weiterführende theoretische Untersuchungen über die potenzielle Systemleistungsfähigkeit motiviert. Unter Berücksichtigung von kommerziell erhältlichen MMICs werden verschiedene Schaltungstopologien auf der Grundlage des Signal-Rausch-Verhältnisses verglichen. Sowohl für sequenzielle als auch für parallele Ansteuerung der Antennenkeulen wird eine deutliche Leistungssteigerung ermittelt. Diese Verbesserungen hängen maßgeblich von der Verfügbarkeit geeigneter MMICs und einer zuverlässigen Aufbau- und Verbindungstechnik ab. Das vorliegende Frontend-Konzept kann auf Grund seiner Flexibilität leicht an derlei zukünftige Entwicklungen angepasst werden.

\section{Introduction}

Modern automobiles are equipped with an increasing number of electronic assistance systems to support the driver. In this context automotive radars gained a lot of interest in the past. This paper reports on a frequency modulated continuous wave (FMCW) sensor, which consists of a planar antenna, millimeter-wave monolithic integrated circuits (MMIC), and a phase locked loop (PLL). Printed circuit board technology and usage of MMIC offer fundamental advantages for system integration and mass production. Because of the fast progress of the MMIC performance a flexible sensor concept is useful to quickly integrate new chip sets.

\section{Prototype of the frontend}

\subsection{Antenna}

The sensor comprises a bistatic antenna system based on a planar microstrip patch array (Metz et al., 2001b). The excitation of the RX antenna is performed by a modified Rotman lens, which sets the phase and amplitude distribution to the 33 columns of the array according to the selected beam 


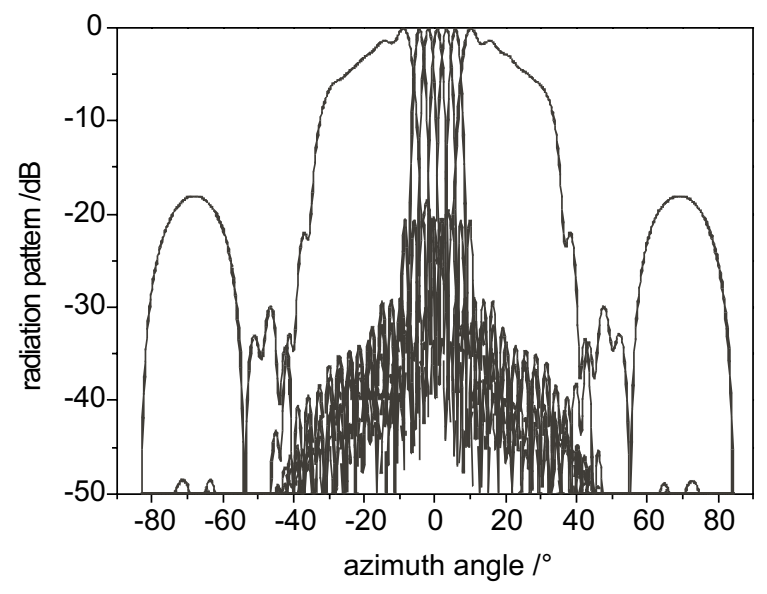

Fig. 1. Simulated RX-antenna pattern.

( $H$-plane). As shown in Fig. 1, the antenna system possesses five beams of $2.7^{\circ}$ width at $26.6 \mathrm{dBi}$ average gain. The distributed excitation for cut-in detection is designed to concentrate the power to the array center region. Hence, the effective array aperture is reduced, which results in a beam broadening.

The TX antenna illuminates permanently the entire field of view. With a half-power beamwidth of $22^{\circ}$, the resulting radiation pattern exhibits a gain of $23 \mathrm{~dB}$.

Both the RX- and the TX-antenna have columns of 31 series-fed patches which determine the $E$-plane characteristic. Each patch column is fed at its center element by aperture coupling.

\subsection{Transceiver unit}

Figure 2 illustrates the architecture of the transceiver unit including PLL and antennas (Jacob et al., 2002). A voltagecontrolled oscillator (VCO) generates a $12.75 \mathrm{GHz}$ signal, which is amplified and tripled on-chip (CHV2242) to $38.25 \mathrm{GHz}$. The oscillator is coupled to a medium- $Q$ resonator consisting of three coupled half-wave lines, as suggested in (Camiade et al., 2000). The oscillator exhibits a free-running phase noise of $-75 \mathrm{dBc} / \mathrm{Hz} @ 100 \mathrm{kHz}$ and a tuning range exceeding $150 \mathrm{MHz}$.

The multifunction chip (CHU2277) combines a frequency doubler and amplifiers. It has two $76.5 \mathrm{GHz}$ ports with an output power of $13 \mathrm{dBm}$ and $9 \mathrm{dBm}$, respectively. These feed the TX antenna and the local-oscillator (LO) port of the receiving mixer, respectively.

The integrated in-phase and quadrature mixer (CHM2177) down-converts the signal of the receiving antenna for further signal processing. Sequential lobing of the seven RXantenna beams is provided by means of $\mathrm{p}-\mathrm{i}-\mathrm{n}$ switch MMIC. Since single-chip 77 GHz SP7T p-i-n switches are currently not available, two W6P1 p-i-n switches (Putnam et al., 1997) had to be cascaded. Hereby, additional losses in the order of $9 \mathrm{~dB}$ are introduced to each receiving path.

\section{$2.3 \quad$ PLL}

In order to suppress VCO phase noise and improve frequency chirp linearity, it is essential to employ phase-lock techniques as a part of the radar synthesizer. An especially demanding requirement for the stepped FMCW approach is a short settling time in combination with small frequency steps (Mende and Rohling, 1997).

A direct digital synthesizer (DDS) is used as a reference source for the single-loop PLL. Usually the difficulty associated with DDS is their high spurious signal content at higher output frequencies. To alleviate this, the DDS is operated at lower frequencies (4-9 MHz), where the spurious-free dynamic range is sufficiently high. This output is up-converted, filtered, and fed to the phase/frequency detector (PFD), as shown in Fig. 2.

The VCO output at $38.25 \mathrm{GHz}$ is partially coupled into the feedback path and down-converted by an integrated oscillator/mixer MMIC (CHV2241). The output IF signal in the frequency range of 704-784 MHz is amplified and fed to the PFD through a prescaler/divider chain $(N=16)$ for comparison with the reference signal at 44-49 $\mathrm{MHz}$.

Within $300 \mathrm{kHz}$ around the carrier, the phase noise is efficiently suppressed by typically $10-15 \mathrm{~dB}$, yielding a nominal value of $-85 \mathrm{dBc} / \mathrm{Hz} @ 100 \mathrm{kHz}$. The transient behavior of the loop, determined by the loop filter bandwidth, is characterized by settling times of less than $1.5 \mu \mathrm{s}$.

\subsection{Assembly and test}

A $630-\mu \mathrm{m}$-thick alumina substrate carries the RF-electronics consisting of four commercially available MMICs (Camiade et al., 2000), two MMIC p-i-n switches (Putnam et al., 1997), and various passive circuit components. While all RF connections are wire bonded, the DC and IF interconnections are flip-chipped using conductive adhesives. The feed network is supported by a layer of Rohacell to avoid impairment of its electrical characteristics due to package influence.

First functionality tests were conducted in a stationary environment. The processed data is shown in Fig. 3. A corner reflector located at $60 \mathrm{~m}$ and a wall at about $70 \mathrm{~m}$ are clearly visible. A more detailed description of the measurement setup can be found in (Metz et al., 2001a).

\section{Advanced RF-circuit concepts}

Figure 4 depicts different standard radar frontend concepts. These were analyzed similarly to (Jacob et al., 2002), but taking into account recent MMIC developments (Camiade et al., 2002). They were compared with respect to maximum radar range. Other performance aspects as well as circuit complexity are briefly addressed in the following. The transmit and receive blocks, labeled T/R in Fig. 4, include the oscillator with its PLL as well as the receiving mixer, and are assumed to be identical in all cases.

Two antenna configurations are investigated. Monostatic systems require only a single (high gain) antenna for both 


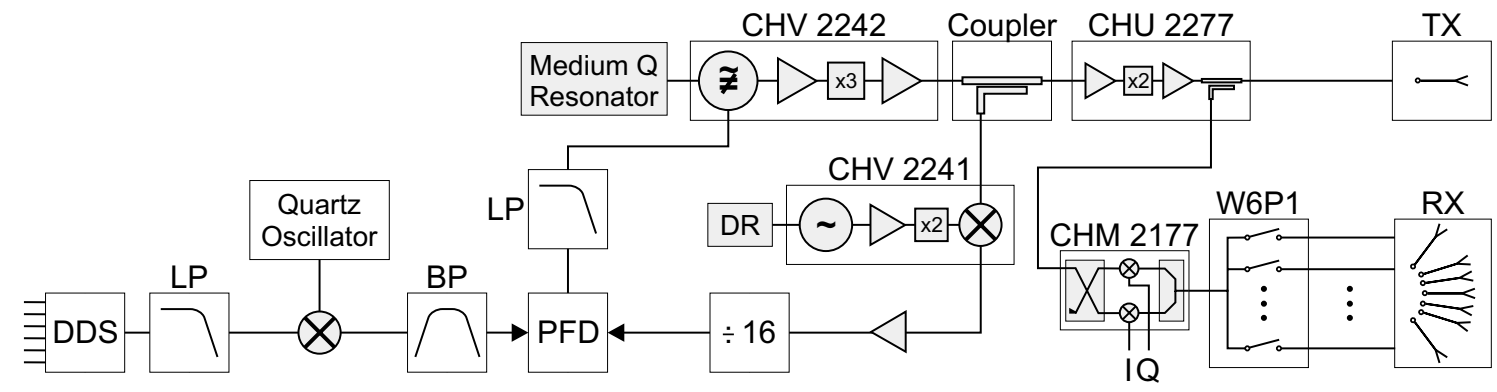

Fig. 2. Block diagram of the sensor.

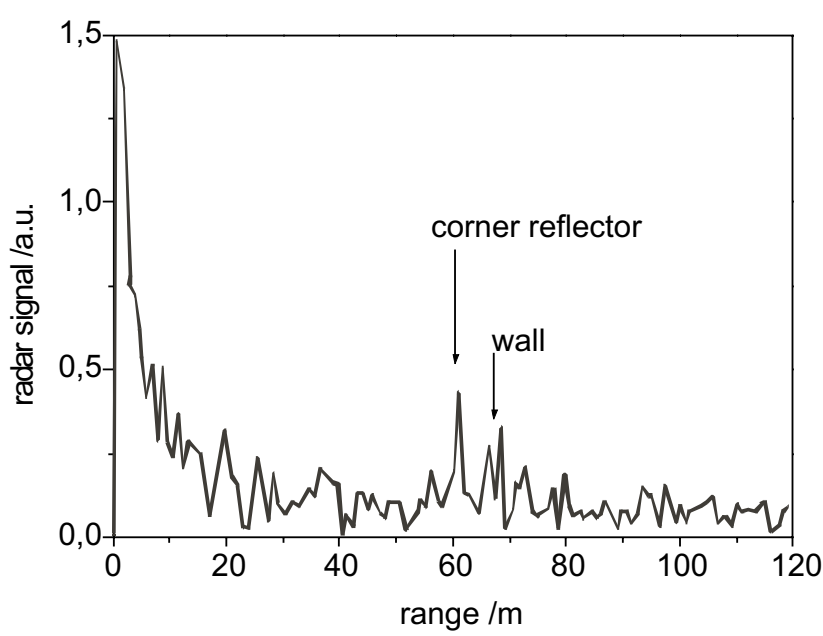

Fig. 3. Measurement result with target at $60 \mathrm{~m}$ and wall at $70 \mathrm{~m}$.

transmit and receive operation. In Figs. $4 \mathrm{a}$ and $\mathrm{c}$ the individual beams are represented by boxes labeled T/R X. The system is small but needs a diplexer to separate the RXand TX-paths. In monolithic integrated system this device could be a hybrid which introduces losses. Bistatic systems use two distinct antennas for transmit and receive, labeled as TX and RX, respectively (see Figs. $4 \mathrm{~b}$ and d). The diplexer and the associated loss can thus be avoided and the RX-/TXdecoupling is improved at the expense of the required space. The TX-antenna can further be designed to simultaneously illuminate the whole field of view. This could be advantageous in terms of signal-to-noise ratio.

The surveillance of a wider angular range with a given (fine) resolution can be achieved by either sequential or parallel lobing. In the former case (Figs. $4 \mathrm{a}$ and $\mathrm{b}$ ) only one $\mathrm{T} / \mathrm{R}$-module is needed that must be sequentially connected to the different antennas by means of a multiplexer. Parallel lobing, in contrast, requires as many receivers as beams for simultaneous signal processing. Obviously, this saves time, an important feature in automotive applications. Also, the loss generally introduced by the multiplexer can be reduced. The drawback is the increased circuit complexity, i.e. the higher number of MMIC.

A comparison shows that the concept with best overall performance combines a bistatic antenna system and paral- lel lobing. It provides good decoupling of the TX- and RXpaths, fast signal detection because of parallel data acquisition, and large radar range because of lower losses. A possible realization based on recently presented MMIC (Camiade et al., 2000, 2002) will therefore be discussed in more detail next. Figure 5 depicts a block diagram of a possible configuration. From the sensor discussed in Sect. 2 and sketched in Fig. 2 only the integrated oscillator/mixer MMIC (CHV2241) and the multifunction chip (CHU2277) are kept. The VCO is replaced by the highly integrated version CHV2243. The output signal is amplified and partially coupled into the PLL-feedback path. The remainder is split to feed both the TX-and the LO-path. The former leads to the novel multifunction chip (CHU3077), which delivers a maximum output power of $17 \mathrm{dBm}$. The latter is connected to the multifunction chip CHU2277. Its two output ports constitute the first stage of the multiplexer. Two active power splitters (CHA2177) in the second stage provide four LOsignals. These feed dual channel mixers (CHM2378) allowing to connect eight antenna ports. To improve the signal-tonoise ratio low noise amplifiers (LNA) (CHA1077) are added in each RX-path.

\section{Maximum radar range}

To evaluate the system performance the frontend can be reduced to the block diagram in Fig. 6. The two-ports exhibit overall gain $\left(G_{T X, R X}\right)$ and noise figure $\left(F_{T X, R X}\right)$ of the entire TX- and RX-path, respectively. They also take into account loss and noise of the antennas. Their directivity is given by $D_{T X}$ and $D_{R X}$, respectively, as shown in the Figure. The LO-noise is not taken into account. The power $P_{R X}$ echoed from a target of radar cross section $A$ at distance $r$ follows from the well-known radar equation (Skolnik, 1980). The signal-to-noise ratio $(S / N)$ at the mixer output is then obtained as $(S / N)=P_{R X} /\left(F_{R X} P_{N}\right)$. Here, $P_{N}=k_{B} T_{a} B$ is the noise power received by the RX-antenna ( $B$ : bandwidth; $k_{B}$ : Boltzmann constant; $T_{a}=290 \mathrm{~K}$ : assumed noise temperature). For given minimum detectable signal to noise ratio $(S / N)_{\text {min }}$ the maximum radar range $r_{\max }$ is obtained from:

$$
r_{\max }=\sqrt[4]{\frac{D_{T X} D_{R X} \lambda^{2} P_{T X} A}{(4 \pi)^{3}(S / N)_{\min } F_{R X} k_{B} T_{a} B}} .
$$




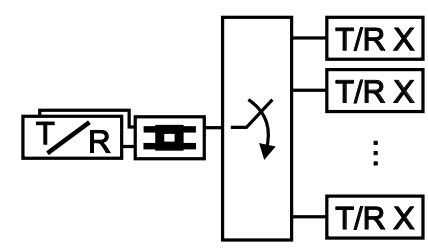

(a) sequential - monostatic

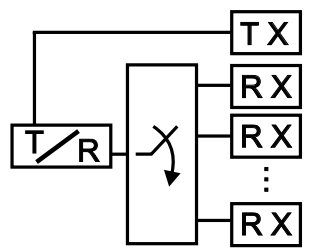

(b) sequential - bistatic

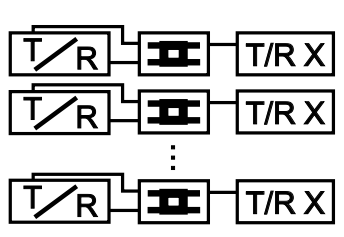

(c) parallel - monostatic

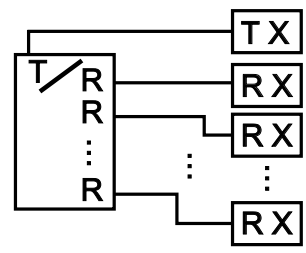

(d) parallel - bistatic

Fig. 4. Different concepts for RF-circuits. (a): Monostatic antenna and sequential processing. (b): Bistatic antenna and sequential processing. (c): Monostatic antenna and parallel processing. (d): Bistatic antenna and parallel processing.

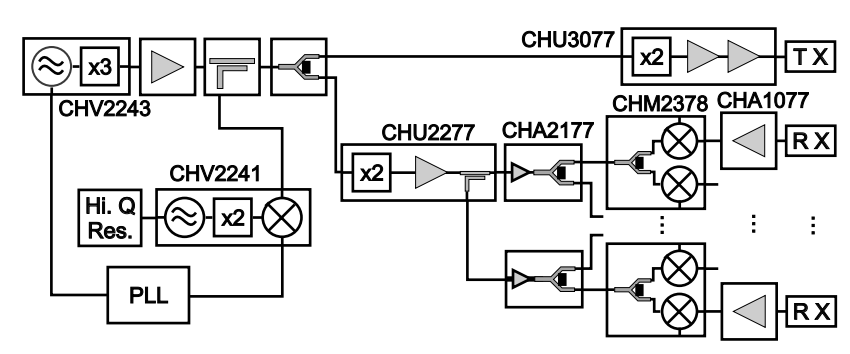

Fig. 5. Bistatic antenna and parallel processing system with latest chip generation.

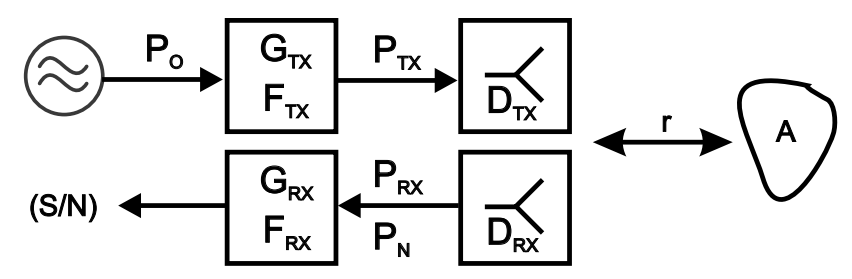

Fig. 6. Block diagram for the determination of the maximum radar range.

Here, $\lambda$ is the wavelength in free space. To estimate the radar range of the system in Fig. 5 the following assumptions were made. The attenuation of the bond wires and the transmit antenna reduce the output power $P_{O}$ of the CHU3077 chip to $P_{T X}=15 \mathrm{dBm}$. The directivity of the TX-and RX-antenna are $27 \mathrm{~dB}$ and $36 \mathrm{~dB}$, respectively. The losses of the RXantenna are estimated to $10 \mathrm{~dB}$. At the center frequency of $76.5 \mathrm{GHz}$ the required signal bandwidth is $B=150 \mathrm{kHz}$. A worst case target with a radar cross section of $A=1 \mathrm{~m}^{2}$ is considered; this corresponds approximately to a pedestrian. The characteristics of the RX-antenna $(F=10 \mathrm{~dB}$, $G=-10 \mathrm{~dB}$ ), the LNA $(F=4 \mathrm{~dB}, G=17 \mathrm{~dB}$ (Camiade et al., 2002)), and the mixer allow to calculate the cascaded noise figure. The dependence of the mixer noise figure on output frequency (IF) is taken as specified in (UMS, 2001). Figure 7 shows achievable radar ranges for configurations with varying numbers of LNA in the RX-paths and for two minimum signal-to-noise ratios $(S / N)_{\min }$. The left ordinate applies for $(S / N)_{\min }=10 \mathrm{~dB}$, the right one for $(S / N)_{\min }=0 \mathrm{~dB}$. The first configuration without LNA shows a maximum range which varies between 40 and $110 \mathrm{~m}$

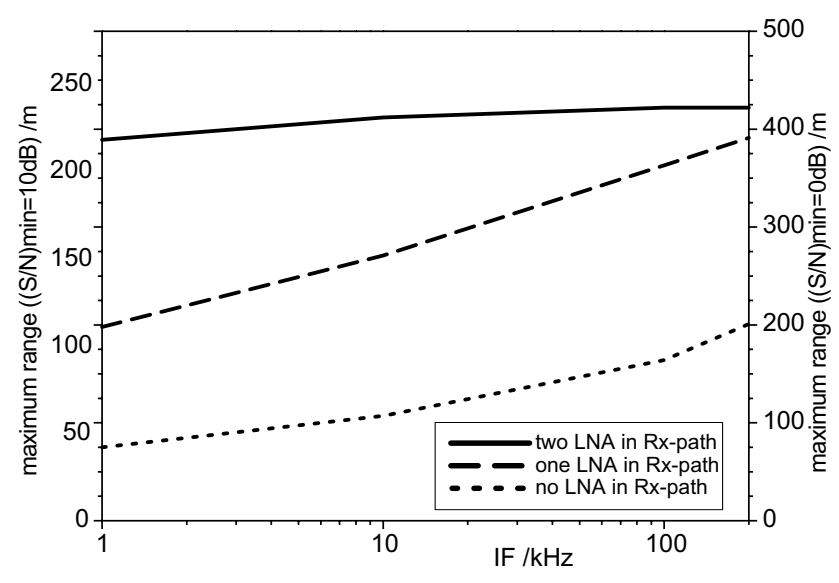

Fig. 7. Maximum radar range of the system in Fig. 5 with $(S / N)_{\min }=10 \mathrm{~dB}$ and $(S / N)_{\min }=0 \mathrm{~dB}$.

(resp. 75 and $200 \mathrm{~m}$ ) as a function of IF. Adding one LNA in each RX-path yields significant improvement with a maximum range between 110 and $220 \mathrm{~m}$ (resp. 200 and $390 \mathrm{~m}$ ). A second LNA also increases the range and further reduces the IF dependence. The achievable range now varies between 220 and $240 \mathrm{~m}$ (resp. 390 and $420 \mathrm{~m}$ ).

In summary, an IF of $200 \mathrm{kHz}$ and a LNA in each RXpath seems to be a good compromise in terms of system performance. Indeed, a small radar cross section such as from a pedestrian is detectable at $200 \mathrm{~m}$ even for $(S / N)_{\min }=$ $10 \mathrm{~dB}$.

\section{Conclusions}

In this paper, a fully integrated FMCW radar sensor is presented, built from available MMIC components. Laboratory and stationary tests demonstrate the performance of this prototype. The flexible planar concept of the sensor is best suited to accommodate future MMIC developments. The latest chip generation promises significant improvement of sensor performance. Additionally, operation at higher IF appears as an effective means to substantially increase the maximum radar range. 


\section{References}

Camiade, M., Domnesque, D., Quarch, Z., and Sion, A.: Fully MMIC-based front end for FMCW automotive radar at $77 \mathrm{GHz}$, Proc. 30th EuMC, Paris, France, pp. 9-12, 2000.

Camiade, M., Baglieri, D., Cortese, P., Domnesque, D., Sion, A., Beilenhoff, K., and Daembkes, H.: Monolithic microwave and MM-wave ICs for automotive applications - measures for cost reduction, IEEE MTT-S Int. Microwave Symp. Workshop Notes Automotive Radars \& Prospective Circuit / Antenna Technologies from "Car Collision Avoidance" to "Autonomous Driving", Seattle, WA, 2002.

Jacob, A. F., Metz, C., Grubert, J., Heyen, J., and Stange, L. C.: Advanced Radar Concepts for Automotive Applications, IEEE MTT-S Int. Microwave Symp. Workshop Notes Automotive Radars \& Prospective Circuit / Antenna Technologies from "Car Collision Avoidance" to "Autonomous Driving", Seattle, WA, 2002.

Mende, R. and Rohling, H.: A high performance AICC radar sen- sorconcept and results with an experimental vehicle, Radar'97, Järfälla, Sweden, pp. 21-25, 1997.

Metz, C., Grubert, J., Heyen, J., Jacob, A. F., Janot, S., Lissel, E., Oberschmidt, G., and Stange, L. C.: Fully integrated automotive radar sensor with versatile resolution, IEEE Trans. Microwave Theory Tech., 49, 12, pp. 2560-2566, Dec. 2001a.

Metz, C., Lissel, E., and Jacob, A. F.: Planar Multiresolutional Antenna for Automotive Radar, Proc. 31st EuMC, London, UK, 1, pp. 335-338, 2001b.

Putnam, J., Barter, M., Wood, K., and LeBlanc, J.: A monolithic GaAs PIN switch network for a $77 \mathrm{GHz}$ automotive collision warning radar, IEEE MTT-S Int. Microwave Symp. Dig., 2, pp. 753-756, 1997.

Skolnik, M. I.: Introduction to radar systems, McGraw-Hill Inc., 1980.

United Monolithic Semiconductors S.A.S.: Data sheet CHM2378, Ref. DSCHM23781074-15-Mar.-01, United Monolithic Semiconductors S.A.S., France, 2001. 